\title{
Arranjo e descrição arquivística em processos judiciais
}

Tassiara Jaqueline Fanck Kich

\begin{abstract}
Mestranda do Programa de Pós-Graduação Profissionalizante em Patrimônio Cultural da Universidade Federal de Santa Maria (UFSM) Arquivista do Tribunal de Justiça do Rio Grande do Sul.
\end{abstract}

Glaucia Vieira Ramos Konrad

Doutora em História Social do Trabalho pela Universidade Estadual de Campinas. Professora do Departamento de Documentação e do Programa de Pós-Graduação Profissionalizante em Patrimônio Documental da Universidade Federal de Santa Maria (UFSM).

Apresenta proposta de arranjo e descrição para processos judiciais de guarda permanente do acervo do Arquivo Judicial do Tribunal de Justiça do Rio Grande do Sul. Este acervo é composto por fontes documentais, que permitem estudos sociais, culturais, jurídicos e históricos. Para organização e acesso às informações, os processos foram arranjados e descritos, aplicando as funções arquivísticas, de acordo com as necessidades e especificidades dos arquivos judiciais. Considerando a Norma Brasileira de Descrição Arquivística, definiu-se o arranjo dos documentos nos níveis fundo, seção, subseção, série e processo, os quais foram descritos, conforme os elementos apresentados pela Norma. A descrição proposta foi aplicada em conjunto de processos judiciais representativos da Primeira República (1889-1930). A análise das informações descritas permite relações com fatos e aspectos sociais, políticos e culturais do período histórico considerado, fornecendo aos estudiosos inúmeras possibilidades de pesquisas e permitindo o acesso a relevantes informações constantes nos documentos judiciais.

Palavras-chave: Patrimônio documental; Poder Judiciário; Arranjo; Descrição. 


\section{Archival arrangement and description in lawsuits}

Introduces arrangement and description proposal for lawsuits of custody from the collection of the Archive of the Judicial Court of Rio Grande do Sul. This collection consists of documentary resources that enable social studies, cultural, legal and historical. For organizing and accessing information, the cases were arranged and described by applying the archival functions according to the needs and specificities of the court files. Considering the Brazilian Standard of Archival Description, were defined and described the description levels base, section, subsection, series and process, which were described as the evidence presented by the Standard. The proposed description was applied along the lawsuits representatives of the First Republic (1889-1930). Analysis of the information described allows relations with facts and social, political and cultural aspects from the historical period considered, providing the scholars with numerous opportunities for research and allowing access to relevant information contained in court documents.

Keywords:Documentary Heritage; Judicial Branch; Arrangement; Description.

Recebido em 16.07.2011Aceito em 12.12.2011

\section{Introdução}

Os Tribunais de Justiça são responsáveis pela organização judiciária e pela distribuição da justiça, em primeiro e segundo graus, no nível estadual. No Rio Grande do Sul, a história da Justiça teve início no ano de 1874, com a instalação do prédio do Tribunal da Relação de Porto Alegre, o qual possuía jurisdição sobre as Províncias de São Pedro do Rio Grande do Sul e Santa Catarina.

Atualmente, o Poder Judiciário do Rio Grande do Sul, por meio de seus órgãos, disponibiliza seus serviços à sociedade, avaliando e julgando questões sociais atinentes a pessoas e grupos, utilizando-se, para isso, de processos judiciais. Esses processos, uma vez conclusos, formam o acervo do arquivo do Tribunal de Justiça.

Esse acervo compõe-se de muitos documentos de guarda permanente, caracterizados pelos seus valores informativo e histórico. A 
busca por justiça, evidenciada nesses documentos, permite identificar questões sociais, valores econômicos, identidades étnicas, dentre outras questões que permitem reconstituir e ressignificar a história e a evolução social do Rio Grande do Sul.

Buscando organizar e acessar as informações judiciais, desenvolveuse o presente trabalho, voltado ao arranjo e descrição de processos de guarda permanente do Arquivo Judicial do Tribunal de Justiça do Rio Grande do Sul.

O objetivo central do trabalho constituiu-se na elaboração de um plano de arranjo e descrição para o acervo permanente de processos judiciais. Além disso, buscou-se identificar a estrutura de arranjo e os níveis de descrição; realizar a descrição de processos judiciais referentes ao período da Primeira República, de acordo com a Norma Brasileira de Descrição Arquivística (NOBRADE); e criar meios para o acesso e pesquisa aos documentos tratados e apresentar a relevância das informações sociais, jurídicas e históricas presentes nos processos.

Tal proposta de trabalho surgiu da necessidade prática de formatar, junto ao Arquivo Judicial, o arranjo e a descrição do patrimônio documental, considerando fundamental 0 acesso às informações registradas nessas fontes.

Apesar de considerar a realidade e as necessidades desse Arquivo, o trabalho pode contribuir para as políticas de tratamento e preservação do patrimônio documental de outros órgãos, uma vez que são incentivados os estudos e trocas de experiências entre as unidades do Poder Judiciário, para padronização de muitas políticas e preservação da memória. Além disso, muitos tribunais enfrentam problemas similares relacionados à preservação e difusão das informações judiciais, tornando relevantes as iniciativas que contrapõem tal situação.

\section{Os arquivos judiciais}

Entidades públicas e privadas, pessoas e famílias possuem diversidades de conjuntos documentais que registram fatos e informações de diferentes épocas. Esses documentos compõem o patrimônio documental da humanidade, o qual requer medidas de preservação, acesso e promoção do seu conhecimento, independente da origem, formato ou suporte dos documentos.

Nesse sentido, a Constituição da República Federativa do Brasil de 1988, ao se referir ao patrimônio cultural brasileiro, em seu Art. 216, afirma: "cabem à administração pública, na forma da lei, a gestão da documentação governamental e as providências para franquear sua consulta a quantos dela necessitem" (Redação dada pelo parágrafo $2^{\circ}$. do Art. 216). 
A proteção do patrimônio documental brasileiro encontra respaldo, também, na Lei no. 8.159, de 8 de janeiro de 1991, que define arquivos como:

[...] os conjuntos de documentos produzidos e recebidos por órgãos públicos, instituições de caráter público e entidades privadas, em decorrência do exercício de atividades específicas, bem como por pessoa física, qualquer que seja o suporte da informação ou a natureza dos documentos (Art. $\left.2^{\circ}\right)$.

Os arquivos do Poder Judiciário são considerados documentos públicos e representam um patrimônio para a reconstrução da vida diária e das relações sociais, para a pesquisa e o ensino. Mesmo os processos findos, que não apresentam mais quaisquer possibilidades de recursos, são fontes de elementos de prova e acesso à memória.

A produção de documentos no Judiciário cresce e essa produção, hoje, parece ter relação inversa com a capacidade de gerenciamento dos acervos, gerando acúmulos de documentos que causam prejuízos aos jurisdicionados, pela dificuldade de acesso às informações contidas nos processos judiciais e pela demora, algumas vezes excessiva, na realização de procedimentos que dependem desse acesso. Tal situação dificulta a preservação, difusão e uso das informações contidas nas fontes judiciais.

A bibliografia sobre as fontes documentais do Poder Judiciário revela o reconhecimento quanto à memória que nelas se pode dispor. Nesse sentido, Campos (2001, p. 42-43) discorre:

O importante na preservação dos documentos provenientes do judiciário é a aquisição do conhecimento sobre passado, sobre os dados e informações a respeito do que os homens e mulheres fizeram ou deixaram de fazer, sobre a história e as transformações ocorridas ao longo do tempo. A documentação torna-se, nesta medida, um patrimônio público insubstituível porque são fontes originais das ações político-administrativo, antropológico-culturais, sociais, econômicas e mentais de uma sociedade. Os processos são registros de práticas adotadas. Permitem a desconstrução do passado, o reconhecimento das diferenças que o passado acaba por revelar, as normas e os valores sociais instituídos em seus diferentes contextos, as relações cotidianas estabelecidas entre os gêneros, às normas e regras de conduta social, assim como o seu contrário.

Sob a mesma abordagem e de forma complementar, Nunes (1998, p. 10) afirma:

As fontes históricas revelam fatos que deixaram vestígios do passado, sendo grande sua importância para o ensino das disciplinas jurídicas, fazendo o estudante compreender a evolução do Direito e que a legislação em vigor não brotou repentinamente, mas tem raízes fincadas no passado. Neles, o jurista, tantas 
vezes, encontrará razões que justifiquem seu parecer atual.

Dessa forma, percebe-se que os arquivos judiciais podem constituirse em fontes informacionais relevantes para o direito, a história e à memória de fatos que envolvem a sociedade em diferentes épocas.

\section{Tratamento dos arquivos}

O tratamento dos arquivos representa a aplicação de conceitos teóricos e práticos da arquivologia, a qual vem construindo e sedimentando esses conceitos entre os saberes e fazeres da sociedade.

Entre as funções arquivísticas destacam-se, na abordagem ora apresentada, a classificação e a descrição dos documentos, aplicadas à gestão documental.

A gestão dos documentos é a integração das funções e atividades relacionadas aos arquivos, desde que esses são produzidos até serem eliminados ou recolhidos para guarda permanente. Com a gestão, tornase possível o controle da produção e tramitação dos documentos, garantindo 0 acesso e evitando o acúmulo desnecessário da documentação. Um programa de gestão envolve as três idades de vida dos documentos, ou seja, arquivos correntes, intermediários e permanentes. Esse ciclo de vida define-se de acordo com a frequência e tipo de uso dos documentos.

A classificação de documentos arquivísticos é uma atividade intelectual que os separa de acordo com as funções e atividades da entidade produtora, estabelecendo a relação entre esses documentos. De acordo com Schellenberg (2002), a classificação na fase corrente é básica e necessária à administração, pois reflete as funções e atividades da organização.

A realização do processo de classificação deve ser concomitante com a produção documental, no entanto, muitos conjuntos e/ou fundos não recebem tal tratamento e apresentam documentos acumulados sem qualquer organização. Nesse caso e correspondendo a documentos de valor secundário (arquivo permanente), é apresentado por muitos autores - arranjo documental como procedimento a ser realizado para a classificação nesses arquivos.

Barros (2010) aborda a diferenciação entre a classificação e o arranjo como um problema terminológico e conceitual criado a partir de 1950, com a obra de Schellenberg. Barros analisou os conceitos de descrição, classificação e arranjo em seis manuais/livros, sendo que no Manual de Arranjo de Descrição de Arquivos de Muller, Feith e Fruin (Ed.1 1898) e no $A$ manual of archive administration including the problems of war archives and archive making (1. ed. 1922) de Sir Hillary Jenkinson, não existia diferença entre as funções. Na obra analisada, Modern Archives: Principles and Techniques (1. ed. 1956), Schellenberg é um dos primeiros a separar a classificação e o arranjo, relacionando a primeira com os arquivos administrativos e o segundo com os arquivos históricos. Barros ainda explica que a separação acontece porque começam a dividir- 
se as atividades típicas dos arquivos administrativos contemporâneos e dos arquivos histórico-culturais, e que até hoje é possível encontrar autores que colocam o arranjo e a classificação como sinônimos e outros que os abordam como diferenciados.

Assim, considerando a inferência de Schellenberg (2002), passa-se a considerar arranjo o procedimento de organização adotado nos arquivos permanentes.

Documentos organizados segundo a estrutura lógica definida no arranjo são facilmente localizados por representarem a produção dos documentos. A classificação ou o arranjo são fundamentais à descrição.

A descrição arquivística é realizada, costumeiramente, nos arquivos permanentes, permitindo dar maior visibilidade aos conjuntos documentais existentes, direcionando-se ao público interno e/ou externo à instituição.

A partir de elementos caracterizadores dos documentos, a descrição, de acordo com Castanho et al. (2006), permite a identificação e, principalmente, a divulgação das informações arquivísticas. Esse processo culmina com a elaboração de instrumentos de pesquisa, a partir do conteúdo de documentos de arquivo.

A Norma Geral Internacional de Descrição Arquivística (ISAD(G)) estabelece as diretrizes para o processo descritivo, fornecendo elementos que buscam a padronização do mesmo. Baseada em princípios teóricos arquivísticos, a norma fornece elementos que devem ser considerados na realização da descrição e é, atualmente, referência mundial nesse processo. "A norma permite a criação de conjuntos de descrição coerentes e aplicáveis a todos os tipos de arquivos, fundos ou documentos" (CASTANHO et al., 2006, p. 47).

De maneira semelhante, a Norma Brasileira de Descrição Arquivística (NOBRADE) representa a tentativa de padronização das rotinas descritivas apresentadas pela $\operatorname{ISAD}(\mathrm{G})$ em nosso país. A NOBRADE (2006) possui 28 elementos de descrição, entre os quais sete são obrigatórios: código de referência, título, data(s), nível de descrição, dimensão e suporte, nome(s) do(s) produtor(es) e condições de acesso (apenas para as descrições nos níveis 0 e 1 ).

O processo de normalização da descrição, a partir de diferentes normas e estudos, representa a busca pela padronização e consistência das ações arquivísticas.

\section{0 arquivo do Tribunal de Justiça do Rio Grande do Sul}

No Poder Judiciário do Rio Grande do Sul, o aumento de ações em tramitação e arquivamento é acompanhado da preocupação quanto à localização, guarda e tratamento dos autos findos. Quanto a isso, Axt (2004, p. 334-335) explica:

No Rio Grande do Sul, o tratamento das fontes judiciais não vinha recebendo abordagem sistemática até a bem pouco tempo. No passado, determinou-se o envio de toda a 
documentação de caráter judicial ao Arquivo Público do Estado que, se estima, abriga mais de seis milhões de documentos judiciais, produzidos, sobretudo, entre o século XVII e a década de 1950 do século XX. Cabe, todavia, ressaltar que o Arquivo Público não recebeu a totalidade da documentação judicial produzida durante essa quadra. Com efeito, também o Arquivo Histórico do Estado abriga importantes fontes documentais, tais como os relatórios da Presidência do Tribunal de Justiça anteriores a 1930, correspondências de Juízes com o Presidente da Província no Império e, até, processos. Além disso, nem toda a documentação de primeira instância seguiu para a Capital, permanecendo fragmentos, por vezes consideráveis, nos fóruns. Esta documentação residual foi parcialmente extraviada, ou se encontra distribuída pelos arquivos dos fóruns e pelos arquivos municipais, sendo este, por exemplo, o caso do Arquivo Municipal de Santa Maria, que reúne processos iniciados no século XIX. (...) Da década de 1950 em diante, muito embora existam ainda alguns processos mais recentes guardados no Arquivo Público, os processos judiciais deixaram de ser enviados ao Arquivo Público do Estado, sob o aparente argumento de que a capacidade de armazenagem desta instituição se esgotara. Destarte, a documentação judicial passou a ser acomodada, via de regra, nos fóruns.

Os fóruns, contando com os processos não remetidos ao Arquivo Público do Estado antes ou após a década de 1950, também passaram a apresentar acúmulos de documentos que preocupavam a administração do Poder Judiciário.

Muitas soluções foram abordadas, inclusive a eliminação de autos sem valor histórico, prática combatida por historiadores e pela inexistência de respaldo legal. A microfilmagem dos documentos era considerada cara e tecnicamente complicada. Ao mesmo tempo, as comarcas pressionavam a administração para a retirada da documentação que ocupava o espaço físico necessário às suas atividades. Com isso, optou-se por centralizar, em Porto Alegre, os processos oriundos de todo o Estado. Para isso, foi escolhido um prédio onde funcionara uma revenda de automóveis e realizado um processo licitatório, que culminou na contratação de uma empresa prestadora de serviços, destinada a transferir os processos a este local e registrá-los em um sistema informatizado, para controle de sua localização, além de desarquivar os processos solicitados pelas unidades judiciais, advogados ou partes, para atendimento de suas necessidades (TEDESCO, 2005).

Atualmente, o controle e execução das atividades são realizados por equipe de servidores e estagiários do próprio Tribunal de Justiça. Continua o desenvolvimento, principalmente do arquivamento e desarquivamento 
de processos, ou seja, a guarda de processos findos no acervo e, conforme as solicitações das varas de origem, sua localização e reenvio para as mesmas, seguido do retorno depois de usados os processos. 0 volume da documentação, superior a dez milhões de processos, e o grande número de solicitações dificultam a implementação efetiva de políticas arquivísticas, ocasionando, muitas vezes, dificuldades, inclusive na localização dos documentos.

As determinações da Tabela de Temporalidade definem os autos a serem eliminados ou preservados de forma permanente. Atualmente, muitos processos que se enquadram nos requisitos da Tabela de Temporalidade e formam o acervo permanente encontram-se distribuídos em caixas no acervo, reunidos com outros processos com características e destinação diferentes. Por outro lado, alguns considerados muito antigos estão separados em uma pequena sala, para receberem tratamento diferenciado. Aí se encontram, entre outros, alguns documentos de fins do século XVIII.

Muitos desses documentos estão danificados e recebem alguns reparos. Os processos possuem registros de alguns de seus dados no sistema adotado pela empresa prestadora de serviços, mas os dados apresentam muitos erros, principalmente em datas e nomes de partes, pois muitos processos foram escritos a mão. Nesses casos, os dados são corrigidos e os processos acondicionados em caixas-arquivo.

Esses dados registrados, no sistema, eram as únicas informações que permitiam a recuperação e acesso aos processos, visto que não estava em desenvolvimento a descrição dos mesmos, proposta neste trabalho. Além disso, os processos não estão classificados ou arranjados, sendo apenas alguns separados por regiões ou comarcas em caixasarquivo.

Os pesquisadores ou interessados que procuram as informações do Arquivo, muitas vezes têm o acesso dificultado, em face da falta de políticas e instrumentos descritivos. Da mesma forma, os próprios servidores sentem dificuldade no gerenciamento desses processos, pela falta de padrões e rotinas de procedimentos.

\section{Metodologia}

Para o planejamento dos procedimentos adotados junto ao acervo permanente, propostos neste trabalho, realizou-se o levantamento e análise da literatura e normas existentes, quanto ao arranjo e descrição, visando à definição de fundos e níveis hierárquicos de arranjo que permitam a descrição dos documentos.

Tal proposta de arranjo e descrição teve aplicabilidade, por meio de um conjunto de processos que permitiram a avaliação da pertinência das questões propostas. O uso de um conjunto de processos como amostra representou a possibilidade de testar as propostas de tratamento arquivístico reunidas, considerando as especificidades dos arquivos judiciais e, neste caso, do Arquivo Judicial do Tribunal de Justiça do Rio Grande do Sul. A partir desse estudo, elaborou-se um instrumento 
orientador, contendo os procedimentos padronizados para o arranjo e descrição dos processos. Além do uso desse instrumento nas políticas do Arquivo Judicial, espera-se que o mesmo possa balizar empreendimentos e novos estudos em mais arquivos judiciais, tão necessitados das políticas arquivísticas nos dias de hoje.

Em função do grande volume de processos de guarda permanente existentes, considerou-se, neste trabalho, apenas a produção dos documentos do período da Primeira República, que se encontram registrados no sistema informatizado do Arquivo Judicial, com a data de abertura ou de autuação do processo entre 15 de novembro de 1889 e 24 de outubro de 1930.

Lopes e Rios (2009) afirmam que a Primeira República corresponde ao período que vai da proclamação do regime republicano, em 15 de novembro de 1889, até a revolução de 1930, com a deposição do Presidente brasileiro Washington Luís, em 24 de outubro de 1930.

A data de abertura ou de início do processo foi o critério considerado para delimitação do universo de pesquisa, pois se acredita que ele reflita os tipos de ações e as questões que geram litígios em diferentes períodos históricos. Destaca-se, todavia, que nem todos os processos iniciados no período da Primeira República tiveram sua conclusão no mesmo período, visto que o tempo de tramitação da ação é indefinido, podendo ultrapassar o limite final dessa fase da história brasileira.

Considerando-se a abertura dos autos entre as datas delimitadas à Primeira República, o sistema do Arquivo Judicial apresentou o registro de 55431 processos. Esse universo foi representado por amostra estatística que, com uma margem de erro de 4\%, resultou no tamanho da amostra, com valor aproximado de 618. Estes foram selecionados, aleatoriamente, entre o universo de processos considerados.

Os processos selecionados estão sendo descritos pela equipe do Arquivo Judicial e permitem a análise de muitas questões e a apresentação de resultados.

\section{Estrutura de arranjo e níveis de descrição}

A descrição de documentos arquivísticos pode considerar diferentes níveis, mais gerais ou particulares, segundo os instrumentos de pesquisa a serem elaborados e as necessidades da instituição considerada. Para relacionar esses níveis e tornar a descrição logicamente compreensível aos pesquisadores, é fundamental definir a estrutura do arranjo.

Além disso, a descrição deve considerar, também, as normas existentes em âmbito nacional e internacional, com a finalidade de proporcionar o compartilhamento das informações e o padrão dos procedimentos adotados. Nesse sentido, a NOBRADE (2006) pressupõe o respeito aos fundos e a descrição multinível, considerando o princípio expresso na $\operatorname{ISAD}(\mathrm{G})$, referente à descrição realizada do nível geral ao particular.

O respeito aos fundos, princípio norteador dos procedimentos arquivísticos, requer, em casos de documentos acumulados sem critérios, 
a definição de fundos que reproduzam o contexto de produção dos documentos e as especificidades das unidades produtoras envolvidas.

A descrição multinível, por sua vez, permite a descrição de acervos, fundos, seções, séries, processos ou itens documentais inseridos num contexto que relaciona os documentos a sua produção.

As informações descritas em níveis gerais não devem ser repetidas em níveis mais específicos da estrutura de arranjo. Com isso, dados constantes de níveis gerais, que não aparecem nos mais específicos, são cabíveis a estes.

Dessa forma, a descrição de processos judiciais findos, tem como premissa a identificação e descrição das unidades ou níveis mais gerais, quais sejam:

[...] acervo da entidade custodiadora (nível 0), fundo ou coleção (nível 1), seção (nível 2), série (nível 3), dossiê ou processo (nível 4) e item documental (nível 5). São admitidos como níveis intermediários o acervo da subunidade custodiadora (nível 0,5), a subseção (nível 2,5) e a subsérie (nível 3,5) (NOBRADE, 2006, p. 11).

A adoção desses níveis depende das especificidades das entidades, pessoas ou famílias descritas. "Nem todos os níveis precisam ser implementados: o nível 0 é útil para descrições gerais da totalidade do acervo de uma entidade custodiadora" (NOBRADE, 2006, p. 11). No caso do acervo da instituição considerada neste trabalho - Poder Judiciário do Rio Grande do Sul - propõe-se a adoção dos níveis fundo, seção, subseção, série e processo.

O fundo Poder Judiciário do Rio Grande do Sul é a entidade produtora e custodiadora de seus documentos. Por sua vez, quanto à seção, propõe-se a separação entre o primeiro e segundo graus de jurisdição da justiça do Estado. Há nítida separação entre as ações originárias do primeiro grau e as originárias do segundo grau (Tribunal de Justiça). Segundo a Constituição do Estado do Rio Grande do Sul de 1989, compete aos tribunais de segunda instância processar e julgar:

[...] as habilitações incidentes nas causas sujeitas a seu conhecimento; os embargos de declaração apresentados a suas decisões; os mandados de segurança, mandados de injunção e "habeas data" contra atos do próprio Tribunal, de seu Presidente e de suas Câmaras ou Juízes; os embargos infringentes de seus julgados e os opostos na execução de seus acórdãos; as ações rescisórias de seus acórdãos e as respectivas execuções; a restauração de autos extraviados ou destruídos, de sua competência; os pedidos de revisão e reabilitação relativos às condenações que houverem proferido; as medidas cautelares, nos feitos de sua competência originária; a uniformização de jurisprudência; os conflitos de 
jurisdição entre Câmaras do Tribunal; a suspeição ou o impedimento, nos casos de sua competência (Enumeração dada pelo Art. 93, inciso V da Constituição do Estado do Rio Grande do Sul de 1989).

Além da competência originária para o julgamento de ações, o segundo grau (Tribunal) tem competência recursal para reexaminar as decisões do primeiro grau, quando destas há recurso interposto por uma das partes. Apesar disso, as ações recorridas mantêm a origem e competência na primeira instância da Justiça Estadual.

Assim, o primeiro e segundo graus representam seções (nível 2) do arranjo proposto. $02^{\circ}$. Grau refere-se apenas às ações originárias dessa instância, ao passo que todas as demais, iniciadas no $1^{\circ}$. Grau, constituem o acervo deste último.

A seção da área administrativa comporta a produção documental destinada a organizar os serviços do Poder Judiciário, como atividadesmeio, que propiciam a prestação da justiça.

Para a descrição de processos judiciais findos, proposta neste trabalho, passou-se a considerar a seção $1^{\circ}$. Grau, por ser o produtor, por meio de suas divisões, dos documentos do arquivo do Tribunal de Justiça, entre os quais os produzidos durante a Primeira República.

Como subseção (nível 2,5), propôs-se a adoção das diferentes Comarcas $^{1}$ existentes no 10 . Grau de jurisdição, atualmente em número de 164 (número instável, visto que novas Comarcas podem ser criadas ${ }^{2}$ ).

A partir daí, as séries (nível 3) foram o foco do arranjo dos documentos. Série é a "subdivisão do quadro de arranjo que corresponde a uma seqüência de documentos relativos a uma mesma função, atividade, tipo documental ou assunto" (ARQUIVO NACIONAL, 2005, p. 153). Em se tratando de processos judiciais, há uma classificação referente aos tipos de ações previstos no ordenamento jurídico processual. Tal classificação foi apresentada e padronizada pelo Conselho Nacional de Justiça (CNJ) por meio das Tabelas Processuais Unificadas do Poder Judiciário, as quais uniformizam a terminologia de classes, assuntos e movimentação processuais no âmbito da Justiça Estadual, Federal, do Trabalho e do Superior Tribunal de Justiça (ONSELHO NACIONAL DE JUSTIÇA - CNJ, 2007).

Entre as classes processuais da Justiça Estadual, apontadas pelo CNJ, estão, em nível mais geral: Juizados da Infância e da Juventude, Procedimentos Administrativos, Processo Cível e do Trabalho e Processo

A Lei $n^{0 .} 7.356$, de $1^{\circ}$ de fevereiro de 1980, dispõe sobre o Código de Organização Judiciária do Estado e estabelece: "Art. 20. - O território do Estado, para os efeitos da administração da Justiça comum, divide-se em Distritos, Municípios, Comarcas e Comarcas integradas. (Redação dada pela Lei no. 7.660/82)" e "§ 10. Cada Comarca, que será constituída de um ou mais municípios, terá a denominação do município onde estiver sua sede. (Redação dada pela Lei no. 7.660/82)".

2 A Lei citada no item anterior também determina: "Art. 30. - A criação de novas Comarcas dependerá da ocorrência dos seguintes requisitos:

a) população mínima de vinte mil habitantes, com cinco mil eleitores na área prevista para a Comarca;

b) volume do serviço forense equivalente, no mínimo, a trezentos feitos, ingressados anualmente;

c) receita tributária mínima igual à exigida para a criação de Municípios no Estado". 
Criminal, entre as quais não foi considerada, apenas, os Procedimentos Administrativos, por possuírem relação com a seção Área Administrativa, não considerada entre as ações propostas. As classes dividem-se em várias subclasses, que especificam o tipo de ação considerada. Também os assuntos processuais padronizados na mesma Resolução permitem definir as questões discutidas nos processos. Todavia, para a definição das séries da estrutura de arranjo, passou-se a considerar as classes acima descritas, sendo as demais especificidades apontadas na descrição no nível Processo.

O nível 4, dossiê ou processo, apresentado pela NOBRADE (2006), permitiu descrever os processos judiciais constituintes do acervo do Arquivo Judicial, considerando as suas especificidades e o contexto de sua produção. Os elementos utilizados e os demais detalhes da descrição também foram analisados.

\section{Descrição de processos judiciais}

A descrição de documentos no nível Processo é relevante ao Poder Judiciário, pois os acervos documentais são constituídos, majoritariamente, de conjuntos dessa natureza. No processo, são encontrados diversos itens documentais juntados para seu andamento e comprovação das ações adotadas, referentes ao caso discutido.

Com a descrição do processo, espera-se demonstrar os casos discutidos e extrair todas as informações que possam levar à pesquisa dos documentos por parte dos usuários. Assim, buscou-se um modelo a ser adotado no arquivo do Tribunal de Justiça do Rio Grande do Sul, de forma padronizada, para a descrição dos diferentes processos judiciais.

Adotaram-se, para isso, os elementos da NOBRADE: código de referência, título, datas, nível de descrição, dimensão e suporte, nomes dos produtores, história administrativa/biografia, história arquivística, âmbito e conteúdo, avaliação, eliminação e temporalidade, idioma, características físicas e requisitos técnicos, unidades de descrição relacionadas, notas sobre conservação, notas gerais, nota do arquivista, data(s) da(s) descrição(ões), pontos de acesso e indexação de assuntos.

A Norma de descrição considerada neste trabalho determina: "informações específicas para determinados gêneros de documentos podem e devem, sempre que necessário, ser acrescidas" (NOBRADE, 2006, p. 19). Assim, por descrever processos judiciais, considerando suas especificidades, foi proposta a adoção de subelementos correspondentes a informações consideradas essenciais ao conhecimento de processos. Os subelementos propostos são: unidade de origem, parte(s) e agente(s) processual(is) para o elemento Nomes do produtores, e número(s), classe, assunto e legislação para o elemento Âmbito e conteúdo.

Acredita-se que os produtores dos processos são as unidades nas quais eles são gerados, as pessoas que atuam nessas unidades, 
responsáveis pelo trâmite e decisões das ações, como juízes, escrivães e outros funcionários dos órgãos, além das pessoas físicas ou jurídicas (partes) que têm uma altercação a ser resolvida e para isso buscam a justiça, e seus advogados (procuradores). Para permitir a pesquisa a partir destas diferentes possibilidades, propôs-se o uso de subelementos: a unidade de origem deve reproduzir fielmente a vara, cartório, juizado ou jurisdição da qual o processo é oriundo, considerando a grafia dos mesmos em diferentes épocas; as partes (apresentadas geralmente na capa dos processos) e os agentes processuais também devem ser descritos, na quantidade existente no processo.

Quanto ao Âmbito e conteúdo, a NOBRADE (2006, p. 39) expõe: "Fornecer aos usuários informações relevantes ou complementares ao Título (1.2) da unidade de descrição". Assim sendo, acredita-se que são informações relevantes à descrição proposta, o(s) número(s) do processo, a classe, o assunto e a legislação considerados. A classe e o assunto representam a classificação processual já mencionada, de acordo com as Tabelas Processuais Unificadas do CNJ, sendo necessária, nesse caso, principalmente para processos antigos, a equivalência do assunto discutido na época com a classificação atual. Por sua vez, a legislação que embasa a ação é apresentada no conteúdo de alguns processos e pode ser rica fonte de pesquisas acerca da aplicação das leis em diferentes épocas, justificando a sua adoção na descrição de processos judiciais.

\section{Considerações finais}

Durante a Primeira República, período de aplicação e análise das propostas de descrição e arranjo, ocorreram litígios e questões sociais nas quais se buscou o Poder Judiciário como meio de resolução de conflitos. Os processos judiciais resultantes não permitem generalizações quanto a fenômenos políticos e sociais, os quais são complexos e dependem das influências do meio, mas propiciam análises que sugerem a relação entre o contexto e o caso estudado.

Dessa forma, os processos descritos a partir do plano proposto revelam questões históricas, sociais e econômicas dos envolvidos. Entre os temas que podem ser discutidos estão as condições econômicas, como riqueza e pobreza, as profissões dos envolvidos, as mulheres e relações de gênero, os roubos, furtos, suicídios, homicídios e outros crimes, os imigrantes, as distinções raciais, o analfabetismo e o ensino, as sucessões e partilhas de bens, entre outros.

A descrição dos processos permitiu observar, também, detalhes relacionados à ortografia de outras épocas, além do uso de materiais, procedimentos e expressões incomuns atualmente, os quais, além de curiosos, podem incitar a pesquisa de profissionais de diferentes áreas.

É por meio dos fatos e ocorrências relatados nos autos, que os momentos são registrados e guardados para a história. Farge (2009) argumenta que os personagens não escolhem aparecer nos documentos, mas o incidente os leva a isso: 
Desconcertante e colossal, o arquivo atrai mesmo assim. Abre-se brutalmente para um mundo desconhecido em que os rejeitados, os miseráveis e os bandidos fazem a sua parte em uma sociedade vigorosa e instável. Sua leitura provoca de imediato um efeito de real que nenhum impresso, por mais original que seja, pode suscitar [...]. Nada a ver com o arquivo; vestígio bruto de vidas que não pediam absolutamente para ser contadas dessa maneira, e que foram coagidas a isso porque um dia se confrontaram com as realidades da polícia e da repressão. Fossem vítimas, querelentes, suspeitos ou delinquentes, nenhum deles se imaginava nessa situação de ter de explicar, reclamar, justificar-se diante de uma polícia pouco afável. Suas palavras são consignadas uma vez ocorrido o fato, e ainda que, no momento, elas tenham uma estratégia, não obedecem à mesma operação intelectual que o impresso. Revelam o que jamais teria sido exposto não fosse a ocorrência de um fato social perturbador. De certo modo, revelam um não dito. Na brevidade de um acidente que provocou a desordem, elas vêm explicar, comentar, relatar como 'aquilo' pôde acontecer em suas vidas, entre vizinhança e trabalho, rua e escadas [...]. O arquivo é uma brecha no tecido dos dias, a visão retraída de um fato inesperado. Nele, tudo se focaliza em alguns instantes de vida de personagens comuns, raramente visitados pela história... (FARGE, 2009, p. 12-14.

As ocorrências descritas nos processos judiciais representam fatos e momentos do cotidiano de pessoas em diferentes regiões do Rio Grande do Sul, os quais têm como influência as questões sociais, políticas e econômicas da Primeira República, período de mudanças em busca do desenvolvimento do país.

\section{Referências}

ARQUIVO NACIONAL. Dicionário brasileiro de terminologia arquivística. Rio de Janeiro: Arquivo Nacional, 2005.

AXT, G. Algumas reflexões sobre os critérios para a identificação e guarda dos processos judiciais históricos. Justiça \& História, Porto Alegre, v. 4, n. 7, p. 329-375, 2004.

BARROS, T. H. B. A construção discursiva em arquivística: uma análise do percurso histórico e conceitual da disciplina por meio dos conceitos de classificação e descrição. 132f. Dissertação (Mestrado em Ciência da Informação) - Universidade Estadual Paulista, Marília, 2010. 
BRASIL. Constituição da República Federativa do Brasil de 1988. Brasília, DF, 5 out. $1988 . \quad$ Disponível em: $<$ http://www.planalto.gov.br/ccivil 03/constituicao/constitui\%C3\%A7ao.h tm>. Acesso em: 7 set. 2010.

. Lei no 8.159, de 8 de janeiro de 1991. Dispõe sobre a política nacional de arquivos públicos e privados e dá outras providências. Diário Oficial de União, Brasília, 9 jan. 1991. Disponível em: <http://www.planalto.gov.br/ccivil 03/Leis/L8159.htm>. Acesso em: 4 set. 2010.

Conselho Nacional de Justiça. Resolução no 46, de 18 de dezembro de 2007. Cria as Tabelas Processuais Unificadas do Poder Judiciário e dá outras providências. Diário Oficial de União, Brasília, Poder Judiciário, Brasília, DF, 21 dez. 2007, Seção 1, p. 19.

CAMPOS. P. F. S. A preservação de documentos provenientes do Poder Judiciário. Revista de Ciências Jurídicas e Sociais da UNIPAR, v. 4 n. 1, $2001 . \quad$ Disponível em: $<$ http://revistas.unipar.br/juridica/article/view/1255>. Acesso em: 28 maio 2010.

CASTANHO, D. M. et al. Arranjo e descrição de documentos arquivísticos. Santa Maria: Universidade Federal de Santa Maria, 2006.

CONSELHO INTERNACIONAL DE ARQUIVOS. Comissão ad hoc de Normas de Descrição. $\operatorname{ISAD(G):~Norma~Geral~Internacional~de~Descrição~}$ Arquivística. 2a ed. Estocolmo, Suécia: [s.n.], 2001.

CONSELHO NACIONAL DE ARQUIVOS. NOBRADE: Norma Brasileira de Descrição Arquivística. Rio de Janeiro: Arquivo Nacional, 2006.

CONSELHO NACIONAL DE JUSTIÇA (CNJ). Resolução $\mathrm{n}^{\circ}$ 16, de 18 de dezembro de 2007. Cria as Tabelas Processuais Unificadas do Poder Judiciário e dá outras providências. Diário da Justiça, seção 1, p. 19, 21 dez. 2007.

FARGE, A. O sabor do arquivo. São Paulo: Editora da Universidade de São Paulo, 2009.

LOPES, P. G. M.; RIOS, P. Justiça no Brasil: 200 anos de história. São Paulo: ConJur Editorial, 2009.

NUNES, M. T. A importância dos arquivos judiciais para a preservação da memória nacional. Revista CEJ, Brasília, v. 2 n. 5, mai./ago. 1998. Disponível em: $<$ http://www2.cjf.jus.br/ojs2/index.php/cej/issue/view/15>. Acesso em: 21 maio 2011.

RIO GRANDE DO SUL. Constituição do Estado do Rio Grande do Sul. Porto Alegre, $\quad 3 \quad$ out. $1989 . \quad$ Disponível em <http://www.al.rs.gov.br/prop/Legislacao/Constituicao/CE_Consolidada.ht m>. Acesso em: 21 maio 2011. 
RIO GRANDE DO SUL. Lei $n^{\circ} 7.356$, de 10 de fevereiro de 1980 . Dispõe sobre o Código de Organização Judiciária do Estado, Porto Alegre, $1^{\circ} \mathrm{fev}$. 1980. [Rio Grande do Sul: Assembleia Legislativa do Rio Grande do Sul, 1980]. Disponível em: <http://www.al.rs.gov.br/legiscomp/arquivo.asp?Rotulo=Lei\%20n\%BA\%2 07356\&idNorma=948\&tipo=pdf>. Acesso em: 29 jan. 2011.

SCHELLENBERG, T. R. Arquivos modernos: princípios e técnicas. Rio de Janeiro: Fundação Getúlio Vargas, 2002.

TEDESCO, J. E. Os arquivos judiciais e o Poder Judiciário do Rio Grande do Sul. Justiça \& História, Porto Alegre, v. 3, n. 6, p. 299-313, 2005. 